\title{
MODELAGEM MATEMÁTICA DO CRESCIMENTO DE BIOMASSA E PRODUÇÃO DE ÁCIDO PROPIÔNICO, POR K. MARXIANUS CCT7735
}

\author{
MATHEMATICAL MODELING OF BIOMASS GROWTH AND PROPIONIC ACID \\ PRODUCTION, BY K. MARXIANUS CCT7735 \\ MODELO MATEMÁTICO DEL CRECIMIENTO DE BIOMASA Y LA PRODUCCIÓN \\ DE ÁCIDO PROPIÔNICO, POR K. MARXIANUS CCT7735
}

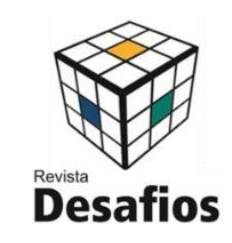

Artigo Original Original Article Artículo Original

\section{Dennis Da Silva Ferreira*1, Pedro Alexandre Da Cruz ${ }^{2}$, Alex Sander Rodrigues Cangussu ${ }^{3}$ \\ ${ }^{1}$ Aluno de Pós-graduação em química, Universidade Federal do Tocantins, Gurupi-TO, Brasil. \\ ${ }^{2}$ Professor Associado do curso de Química Ambiental, Universidade Federal do Tocantins, Gurupi-TO, Brasil. \\ ${ }^{3}$ Professor Adjunto do curso de Engenharia de Bioprocessos e Biotecnologia, Universidade Federal do Tocantins, Gurupi-TO, Brasil.}

*Correspondência: Laboratório de matemática aplicada e química computacional (LMAQC), Universidade Federal do Tocantins, Rua Badejós, Lote 7, Chácaras 69/72, Zona Rural, Gurupi, Tocantins, Brasil. CEP:77.402907.

Artigo recebido em 11/03/2020 aprovado em 06/11/2020 publicado em 06/11/2020.

\section{RESUMO}

O objetivo deste trabalho foi a realização a modelagem cinética do processo de formação de ácido propiônico (Ac. P) e crescimento de biomassa por K. marxianus, através do modelo de Verhuslt e o modelo de Luedeking-Piret e analisar os resultados durante o processo fermentativo. A levedura utilizada foi a K. marxianus CCT 7735 (UFV-3), isolada e armazenada na Universidade Federal de Viçosa. Os componentes do meio foram extrato de levedura, peptona e dextrose. As amostras coletadas de concentração de célula e ácido propiônico foram analisadas por cromatografia líquida de alta eficiência (HPLC) com auxílio do software Scilab. Os dados obtidos durante o processo fermentativo foram ajustados e adaptados aos modelos matemáticos. Houve o crescimento celular em condições de aerobiose, onde nessas condições, a velocidade específica de crescimento $(\mu)$ foi de $0.0925 \mathrm{~h}^{-1}$ e as constante do modelo Luedeking-Piret foram, $\beta=0,000243 \mathrm{~g} \mathrm{Ac.P} \cdot \mathrm{g}_{\text {biomassa }}{ }^{-1} \mathrm{~h}^{-1}, \alpha=0,450639 \mathrm{~g}$ Ac.P $\cdot \mathrm{g}$ biomassa ${ }^{-1}$. A partir da modelagem matemática teve-se a confirmação de que a formação de produto está parcialmente associada ao crescimento celular da levedura.

Palavras-chave: Modelagem matemática, Modelo cinética, Kluyveromyces

\section{ABSTRACT}

The aim of this work was to carry out the kinetic modeling of the propionic acidformation process (Ac. P) and growth of biomass by K. marxianus, through the logistic model and the Luedeking-Piret model and to analyze the results during the fermentation process. The yeast used was K. marxianus CCT 7735 (UFV-3), isolated and stored at the Federal University of Viçosa. The components of the medium were yeast extract, peptone and dextrose. The samples collected from cell concentration and propionic acid were analyzed by high performance liquid chromatography (HPLC). The data obtained during the fermentation process were adjusted and adapted to mathematical models with the aid of the scilab software. There was cell growth under aerobic conditions, where in these conditions, the specific growth rate $(\mu)$ was $0.0925 h^{-1}$ and the constant of the Luedeking-Piret model were, $\beta=0.000243 \mathrm{~g} \mathrm{Ac.P} \cdot \mathrm{g}$ biomass ${ }^{1} h^{-1}, \alpha=0.450639 \mathrm{~g}$ Ac.P $\cdot \mathrm{g}$ biomass ${ }^{-1}$. Mathematical modeling it was, confirmed that product formation is partially associated with yeast cell growth.

Keywords: Mathematical modeling, Kinetic model, Kluyveromyces. 


\section{RESUMEN}

El objetivo de este trabajo fue realizar el modelado cinético del proceso de formación de ácido propiónico (Ac. P) y el crecimiento de biomasa por K. marxianus, a través del modelo logístico y el modelo de Luedeking-Piret y analizar los resultados durante el proceso de fermentación. La levadura utilizada fue K. marxianus CCT 7735 (UFV-3), aislada y almacenada en la Universidad Federal de Viçosa. Los componentes del medio fueron extracto de levadura, peptona y dextrosa. Las muestras recogidas de la concentración celular y el ácido propiónico se analizaron por cromatografía líquida de alta resolución (HPLC). Los datos obtenidos durante el proceso de fermentación fueron ajustados y adaptados a modelos matemáticos. Hubo crecimiento celular en condiciones aeróbicas, donde en estas condiciones, la tasa de crecimiento específico $(\mu)$ fue $0.0925 \mathrm{~h}^{-1}$ y la constante del modelo de Luedeking-Piret fue, $\beta$ $=0.000243 \mathrm{~g}$ Ac.P $\cdot \mathrm{g}$ biomasa $^{-1} \mathrm{~h}^{-1}, \alpha=0.450639 \mathrm{~g}$ Ac.P $\cdot \mathrm{g}$ biomasa $^{-1}$. El modelado matemático confirmó que la formación del producto está parcialmente asociada con el crecimiento de células de levadura.

Descriptores: Modelado matemático, modelo cinético, Kluyveromyces

\section{INTRODUÇÃO}

Várias espécies de leveduras são comumente cultivadas em meios líquidos desde que o meio possa ser assimilado tendo todos nutrientes essenciais para o microrganismo, o que permite um crescimento celular mais rápido. Por exemplo, algumas cepas da levedura Kluyveromyces marxianus têm a maior taxa de crescimento entre células eucarióticas e tolera temperaturas até $52 \circ \mathrm{C}$ (SILVEIRA WB, 2004; DINIZ et al 2012).

O gênero Kluyveromyces está relacionado filogeneticamente com a levedura Saccharomyces cerevisiae, porque eles podem assimilar lactose e usálo para o crescimento, por este fato eles são frequentemente isolados de ambientes lácticos. Adicionado às características acima mencionadas, K. marxianus tem um status "Geralmente Reconhecido como Seguro" (GRAS), o que faz desta levedura uma fonte natural de moléculas bioativas, e atrai o interesse da comunidade científica por suas aplicações biotecnológicas (SILVEIRA WB, 2004; DINIZ et al 2012).

Neste trabalho utilizamos a levedura Kluyveromyces marxianus UFV-3, pois esta levedura mostrou uma alta taxa de rendimento, em condições de alta concentração de lactose e baixo nível de oxigênio indicando um potencial fermentativo superior em relação a outras leveduras do mesmo gênero. Analisando o metabolismo da levedura em meio contendo outros substratos e analisando cinética da produção de ácido propiônico e alguns subprodutos oriundos desta fermentação, variando diferentes parâmetros nas condições do processo fermentativo, podemos contribuir no sentido de fornecer informações que possibilitem subsidiar a modulação da regulação do metabolismo fermentativo via a variação da concentração de oxigênio, e assim definir estratégias experimentais para maximizar a produção industrial (DINIZ et al, 2009; SANTOS et al, 2013).

O Estudo da cinética de um processo fermentativo consiste incialmente em uma análise da progressão dos valores de concentração de um ou mais componentes do sistema de cultivo, em função do tempo de fermentação, e através dos dados experimentais de concentração X (Biomassa), $\mathrm{P}$ (Ácido Propiônico) e S (Substrato) que podemos ter tem-se uma noção do que ocorre durante a fermentação, e quando representado graficamente esses valores de concentração em função do tempo, pode-se traçar uma curva de ajuste dos resultados do processo fermentativo, possibilitando assim uma comparação quantitativa entre condições de cultivo (SCHMIDEL et al, 2001; CANINAS e VIEIRA, 1997).

\section{MATERIAIS E MÉTODOS}

\section{Microrganismo, condições de fermentação e dados experimentais.}

Os dados referentes às condições fermentativas foram cedidos pela UFV- Universidade Federal de Viçosa, de acordo com as informações fornecidas pela UFV a levedura foi isolada da Revista Desafios -v. 7, Especial - PIBIC, 2020 
microbiota entérica de leitões recém-nascido e armazenada no Laboratório de Fisiologia Microbiana do Instituto de Biotecnologia Aplicada à Agricultura, Bioagro / UFV-Brasil. K. marxianus e capaz de assimilar uma variedade de substratos e de crescer a temperaturas elevadas, características desejáveis para probióticos. Um estoque de K. marxianus CCT7735 foi armazenado a $-80^{\circ} \mathrm{C}$ em meio YPD com $20 \%$ de glicerol. Os componentes do meio YPD (em g / L) foram extrato de levedura (10\%), peptona (20\%) e dextrose $(20 \%)$. O meio foi esterilizado a $121^{\circ} \mathrm{C}$ durante $25 \mathrm{~min}$. As amostras foram coletadas e a concentração de células, níveis de etanol, glicerol e ácidos orgânicos, e a produção de AG foram analisadas por cromatografia líquida de alta eficiência (HPLC).

\section{Modelos matemáticos de cinética}

Neste trabalho utilizou-se o modelo de Verhuslt para a análise de crescimento de biomassa, como vemos abaixo:

$$
\frac{d X}{d t}=\mu_{\max }\left(1-\frac{X}{X_{\max }}\right) \cdot X
$$

Onde X é a concentração de biomassa $\left(\mathrm{g} \mathrm{L}^{-1}\right)$, Xmax é a concentração máxima de biomassa $\left(\mathrm{g} \mathrm{L}^{-1}\right), \mathrm{t}$ é o tempo de fermentação (h), $\frac{d X}{d t}$ é a taxa de crescimento [g $\left.\left(\mathrm{L}^{-1} \mathrm{~h}\right)\right]$ e $\mu$ é a taxa de crescimento específico $\left(\mathrm{h}^{-1}\right)$.

Para a formação de produto utilizou-se o modelo de Luedeking-Piret como um processo associado ao semi-crescimento, conforme segue: (Luedeking-Piret, 1959; Wu et al., 2015; GonzálezGarcia et al., 2017).

$$
\frac{d P}{d t}=\alpha \frac{d X}{d t}+\beta X
$$

Onde $\alpha$ é a constante associada ao crescimento (g Ac.P - $g$ biomassa $\left.^{-1}\right), \beta$ é a constante associada à biomassa [g Ac.P.gbiomassa $\left.{ }^{-1} h^{-1}\right)$ ], P é a concentração ácido propiônico $\left(\mathrm{g} \mathrm{L}^{-1}\right), \frac{d P}{d t}$ é a taxa de produção ácido propiônico [g Ac.P $\left.\cdot \mathrm{g}_{\text {biomassa }}{ }^{-1} \mathrm{~h}^{-1}\right]$.

\section{RESULTADOS E DISCUSSÃO}

A Figura 1b) apresenta a taxa de crescimento microbiano $(\mu)$ calculada a partir das equações (1). Na Figura 1 observa-se que a taxa de crescimento microbiano $(\mu)$ tem seus valores mais altos nas primeiras 3 horas de fermentação. No entanto, como a concentração viável da biomassa foi a mais baixa, os valores da taxa de crescimento da biomassa resultante foram baixos. Após 3 horas do experimento, a taxa de crescimento microbiano $(\mu)$ diminuiu significativamente. Com o aumento da concentração de biomassa em função do tempo, o valor de $\mu$ diminuiu ainda mais, e então $\mu$ eventualmente atingiu um valor igual à zero. Após 9 horas, obteve-se $\mu=$ $0.0925 \mathrm{~h}^{-1}$ e seu valor continuou diminuindo para praticamente zero. A concentração de biomassa Figura 1a), no seu máximo, foi incapaz de compensar o efeito de diminuição em $\mu$.

Consequentemente, a produção de biomassa também diminuiu e acabou por cessar como observado na Figura 1a). A formação ácida propiônico fica constante após 5 horas de fermentação constatando o início da fase estacionaria (Fig. 1c), que pode ser confirmado com o decrescimento de $\mu_{\mathrm{p}}$ observado na Figura 1d).

Figura 1. Concentração de biomassa $([\mathrm{X}])$ e taxa de crescimento específico ( $\mu$ ), Concentração de ácido propiônico ([P]), e taxa de formação de produto específico $(\mu \mathrm{p})$, durante as 11 horas de fermentação em condição de aerobiose.
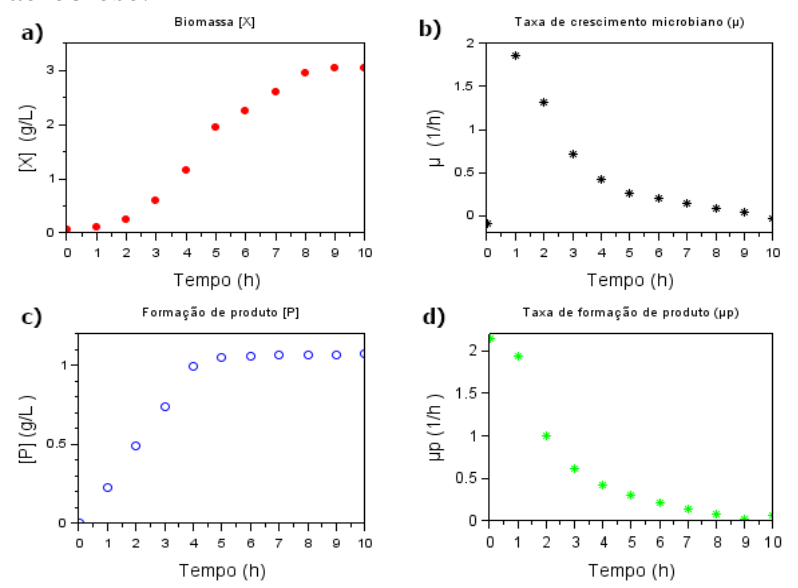

Produção de ácido propiônico parcialmente associado ao crescimento celular

Revista Desafios -v. 7, Especial - PIBIC, 2020 
A produção de ácido propiônico esta parcialmente associada ao crescimento celular, sendo a taxa de formação de biomassa $\left(\frac{d x}{d t}\right)$ e a concentração de biomassa [X] parâmetros do modelo.

A Figura 2, foi obtida durante a fase estacionaria de crescimento, ou seja, quando $\frac{d x}{d t}=0$. Assim a equação (2) resulta na seguinte equação:

$$
\frac{d P}{d t}=\beta X
$$

Portanto, pode-se observar que o aumento da concentração de ácido propiônico é linear durante esta fase.

Figura 2. Aumento da concentração de ácido propiônico linear durante a fase estacionaria de crescimento.

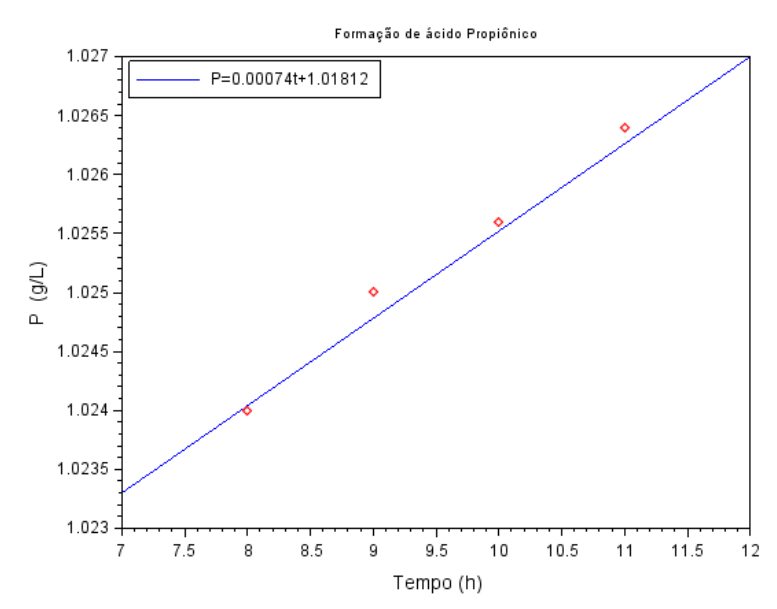

Na Figura 2, a inclinação da reta é, dada por $\frac{d P}{d t}=\beta \mathrm{X}=0,00074$, como $\mathrm{X}$ é constante nessa fase da fermentação, logo $\beta$ pode ser calculado diretamente, obtendo assim $\beta=0,000243$ [g Ac.P $\cdot g$ biomassa ${ }^{-1} h^{-1}$ ]. De posse do valor do parâmetro $\beta$ é possível determinar o valor de $\alpha$ a partir dos perfis calculados de $\frac{d P}{d t}$, fazendo uma aproximação polinomial adequada, e desta forma obtendo um valor médio para $\alpha=0,450639$ [g Ac.P $\cdot$ g biomassa $^{-1}$ ]. A partir desses resultados pode-se concluir que o termo $\alpha$ é o termo dominante, enquanto o termo $\beta$ tende para zero, ou seja o produto é formado durante a fase de crescimento, sendo proporcional para o crescimento da biomassa, onde $\alpha \neq 0$ e $\beta \rightarrow 0$ desta forma tem-se uma produção associado ao crescimento.

Tabela 1. Resumo dos parâmetros cinéticos obtidos na simulação do crescimento da biomassa e produção de ácido propiônico.

\begin{tabular}{|c|c|c|}
\hline \multirow{2}{*}{ Parâmetros } & \multirow{2}{*}{ Unidade } & $\begin{array}{l}\text { Valores de parâmetro } \\
\text { recomendados }\end{array}$ \\
\hline & & Aerobiose \\
\hline$\mu_{0}$ & $\mathrm{~h}^{-1}$ & 2.271 \\
\hline$\Lambda$ & L. g de Acid. Prop ${ }^{-1}$ & 3.175 \\
\hline $\mathrm{A}$ & g de Acid. $\mathrm{P} \cdot \mathrm{g}$ biomassa $^{-1}$ & 0.451 \\
\hline $\mathrm{B}$ & g de Acid. $\mathrm{P} \cdot \mathrm{h}^{-1}$ & 0.00024 \\
\hline$\mu_{\mathrm{x}}$ & $\mathrm{h}^{-1}$ & 0.915 \\
\hline$\mu_{\mathrm{p}}$ & $h^{-1}$ & 0.413 \\
\hline
\end{tabular}

Abaixo temos um gráfico representativo que mostram quão preciso são os modelos cinéticos que descrevem o crescimento celular para a levedura $K$. marxianus, utilizando os parâmetros recomendado pelo modelo de Verhults (Logístico).

Figura 3. - Gráfico comparativo da modelagem matemática versus Dados experimentais para as concentrações de biomassa em condição de aerobiose.

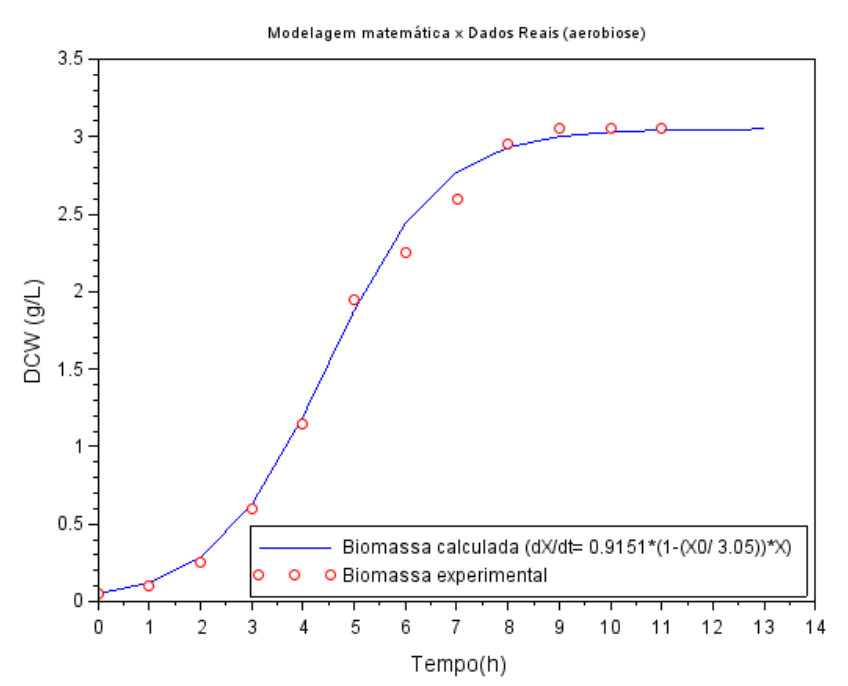

Como observado na Figura 3, o modelo cinético logístico, descreveu muito bem o processo de crescimento celular tendo alta precisão e apresentando uma boa proximidade com os pontos experimentais. 


\section{CONCLUSÃO}

A cinética de produção de ácido propiônico e o crescimento de biomassa durante um processo fermentativo de 11 horas utilizando a levedura $K$. marxianus, na qual avaliou-se a condição de alta aeração como parâmetro. Notou-se um forte efeito inibitório do ácido propiônico sobre a taxa de crescimento de biomassa. Esse efeito foi observado em um dos modelos cinéticos onde apresentou uma taxa de decaimento exponencial à medida que o ácido propriônico se acumulou.

Também foi notado que à produção de ácido propiônico está parcialmente associada ao crescimento de biomassa. Com base nessa análise um modelo matemático foi derivado e seus parâmetros cinéticos foram estabelecidos, e este modelo cinético descreve com precisão os perfis de concentração de ácido propiônico e concentração de biomassa por $K$. marxianus. Variando alguns desse parâmetro do modelo utilizado neste estudo podemos predizer o desempenho genérico para outras espécies de leveduras, facilitando assim 'a otimização de um processo fermentativo para levedura de perfis cinéticos complexos e semelhantes.

\section{AGRADECIMENTO}

O presente trabalho foi realizado com o apoio do Conselho Nacional de Desenvolvimento Científico e Tecnológico - CNPq - Brasil, e da Universidade Federal de Viçosa (UFV).

Todos os autores declararam não haver qualquer potencial conflito de interesses referente a este artigo.

\section{REFERÊNCIAS}

SILVEIRA WB. Ethanol production in permeate of cheese whey by Kluyveromyces marxiamus UFV-3. M.S. Thesis. Viçosa, Mina Gerais, Brasil: Universidade Federal de Viçosa;2004.

DINIZ, SANTOS. R.H et al. Metabolismo de lactose em Kluyveromyces marxianus UFV-3 e Kluyveromyces lactis JA6. 2009.

DINIZ, R.H.S, SILVEIRA., FIETTO, LG., PASSOS, F.M.L, The high fermentative metabolismo of kluyveromyces marxiamus UFV-3 relies on the increased expression. Of key lactose metabolic enzymes.Antonie van Leeuwenhock 101 (3), 541$550,2012$.

DOS SANTOS, CANAZART. V. et al. Kinetics of growth and ethanol formation from a mix of glucose/xylose substrate by Kluyveromyces marxianus UFV-3. Antonie Van Leeuwenhoek, v. 103, n. 1, p. 153-161, 2013.

SCHMIDELL, W.; LIMA, U.A.; AQUARONE, E.; BORZANI, W. Biotecnologia Industrial. São Paulo, Edgard Blücher Ltda, vol.2, 2001.

CANINAS, N.P;VIEIRA, A.F. Curvas de crescimento e otimização de um processo industrial de fermentação.1997.

LEITE, TEXEIRA. M et al. Otimização da produção do ácido láctico através da fermentação do soro de queijo por Lactobacillus helveticus. 2006.

BURGOS-RUBIO,C; OOS, M. R; WANKAT, O. C. Kinect study of the conversion of diferente substrates to lactic acid using Lactobacillus bulgaricus. Biotechnology Progress, v. 16, p.305-314, 2000.

AMRANE, A.; PRIGENT, Y. Analysis of growth and production coupling for batch cultures of Lactobacillus helveticus with the help of an unstructured model. Process biochemistry, v. 34, n. 1, p. 1-10, 1999.

GOMES, M. C. Modelos biomatematicos Crescimento com regulação em reprodutores contínuos. Faculdade de ciência da universidade de Lisboa, 2003. 